\title{
Compressed Air Discharge from a Blowing Unit
}

\author{
G.L. Antinori and M. Spiga* \\ Department of Industrial Engineering, University of Parma, Italy
}

\begin{abstract}
This paper aims at investigating, both through a theoretical and an experimental analysis, the discharging phase of a blowing unit of compressed air, used for the industrial production of plastic made bottles. The proposed mathematical model leads to a system of differential equations describing the flow through an open system. The solution was found by numerical simulations using the software Matlab, determining the gas density, pressure, temperature and mass flow rate, as functions of time. The pressure loss across the down flow has been tackled with a theoretical investigation, determining the mechanical loss coefficient $\beta$ and evaluating the effect of these losses on the emptying time of the blowing unit. The numerical results agree with the real discharging times obtained by experimental tests, and the proposed improvements allow to reduce loss of pressure and the emptying time of $35 \%$ and $20 \%$ respectively.
\end{abstract}

\section{INTRODUCTION}

The excellent level, in terms of quality and productivity, reached by industrial bottling lines, in particular the PET bottles lines, proves that the interest in bottling industries, in the last years, is increasing.

The blowing machine here examined is based on an optimised frame, including both the oven for pre-shaped bottles heating and the stretch-blowing units. These ones are mounted on a rotating platform on which the pre-shaped bottles are conveyed, after the heating phase, and the formed bottles evacuation accomplished.

In this paper we deal with one of the main problems of the compressed air discharging phase, that is the reduction of the required time. Even if it doesn't influence the quality of the shaped bottles, it can affect the machine efficiency. With this purpose in mind, problems related to turbulent flux of a gas in not stationary conditions are considered from a theoretical point of view, with particular attention to the quantification of pressure losses and to their influence on the discharging time. On this regard, it is possible to notice a lack of reference in literature; there are no published papers concerning similar or related work by other authors. Finally, we aim at optimizing the discharging phase by acting on the more significant discharge channel obstructions.

The goals of this paper are:

- the analysis of the gas discharging path with a particular attention to geometry and obstructions;

- $\quad$ the proposal of mathematical model able to simulate the discharging phase;

- $\quad$ the evaluation of the loss of pressure coefficient $\beta$ (taking account of both concentrated and distributed losses);

- the improvement of the channel geometry aimed at reducing the discharge phase time.

*Address correspondence to this author at the Department of Industrial Engineering, University of Parma, Viale G.P. Usberti 181/A, 43100 Parma, Italy; Tel: +39 521 905855; Fax: +39 521 905705;

E-mail: marco.spiga@unipr.it

\section{ANALYSIS OF THE GAS OUTFLOW}

During the platform rotation, on the blowing units the stretch-blowing and air exhaust processes occur (Fig. 1). The discharging phase of the compressed air from the blowing unit occurs after the stretch-blowing phase, when the bottle has been already shaped.

A solenoid valve controls the compressed air inlet into the blowing unit for the bottle filling. Once the valve is closed, an air volume (including the bottle, the blowing nozzle, a double effect cylinder in which is located the stem for the bottle stretching, a flexible duct and a valve control unit) is isolated. After the stretch-blowing phase, the compressed air reaches a thermodynamic equilibrium with a temperature of $10{ }^{\circ} \mathrm{C}$ and a pressure of 37 bar (the blow moulding process takes place at a temperature around $3{ }^{\circ} \mathrm{C}$ ). These conditions have been measured by means of thermocouples and manometers [1]. The discharging phase starts at the opening of the solenoid valve. The compressed air flows through a second flexible duct which connects the valve control unit with a muffler, which reduces the acoustic noise caused by the gas ejection. A cooling unit is installed, aimed at reducing the air temperature and its aptitude to keep humidity, so that the risk of condensation is decreased.

The mathematical model considers a thermodynamic system constituted by a gas in a tank. At first the discharge valve is closed and the tank contains a gas whose absolute pressure is higher than the atmospheric pressure. Once the discharge valve is opened, the discharging of the gas into the atmospheric environment is studied, being well-known the volume of the tank, the exit gas cross-section, the initial and boundary thermodynamic conditions and the nature of the gas.

The following hypotheses are assumed:

the gas is compressible with uniform physical properties;

the process is adiabatic;

the pressure head is described by introducing the mechanical loss coefficient $\beta[2,3]$, defined as: 


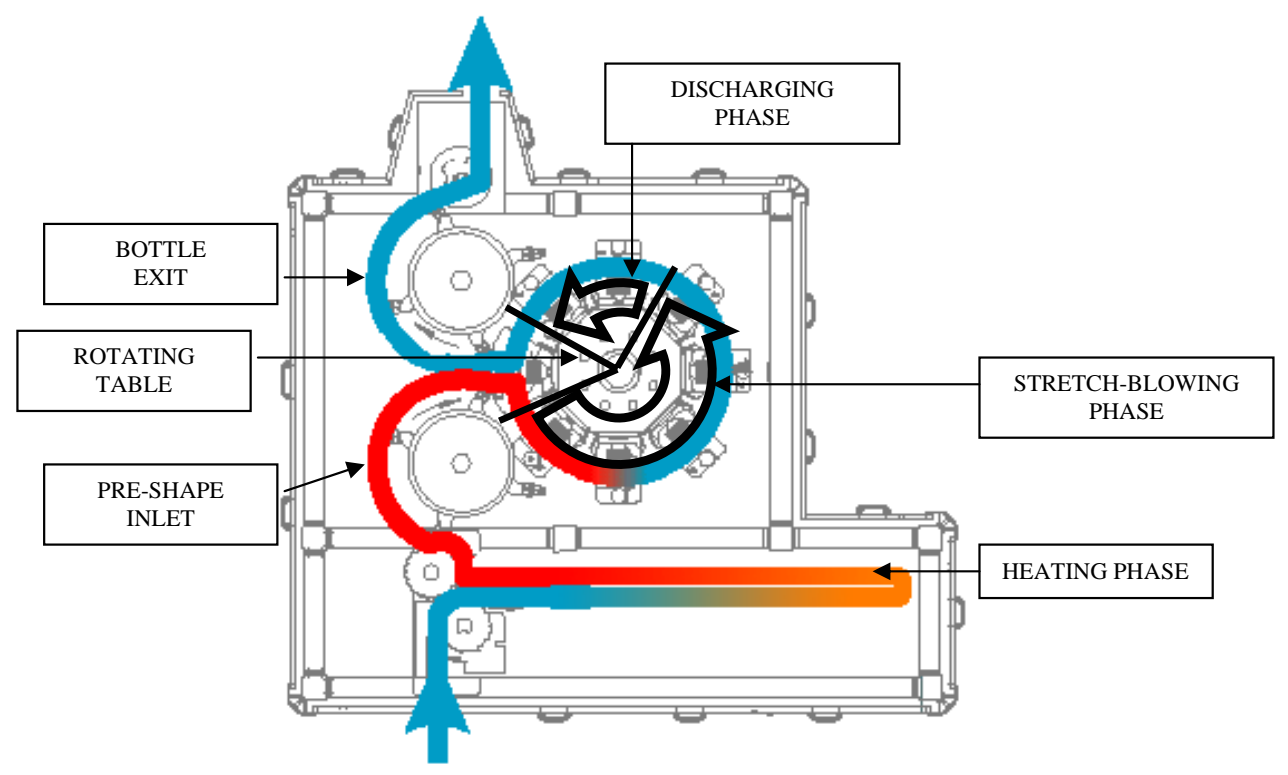

Fig. (1). Main phases of the process.

$$
\frac{p-p_{o}}{\rho}=\beta \frac{W^{2}}{2}
$$

In this model the mechanical losses, both concentrated and distributed, are located exactly in the exhaust section, which acts, in this way, as the only obstruction to the down flow. The mechanical loss coefficient $\beta$, defined in Eq. (1), connects gas pressure and density just upstream the exhaust section with gas pressure downstream and average velocity on the exhaust section. The discharging phase is extremely fast, hence the transformation can be considered adiabatic.

The parameters used in simulating the discharging process from the blowing machine, are [4] $\gamma=1.4, \mathrm{R}=$ $287.041 \mathrm{~J} / \mathrm{kgK}, \mathrm{c}_{\mathrm{v}}=716.4 \mathrm{~J} / \mathrm{kgK}, \mathrm{V}=1.768 \times 10^{-3} \mathrm{~m}^{3}, \mathrm{~S}=$ $1.767 \times 10^{-4} \mathrm{~m}^{2}, \mathrm{p}_{\mathrm{in}}=37 \mathrm{bar}, \mathrm{p}_{0}=1.01325 \mathrm{bar}, \mathrm{T}_{\mathrm{in}}=10^{\circ} \mathrm{C}$. For the ideal gas, the initial density would be $\rho_{\text {in }}=45.52 \mathrm{~kg} / \mathrm{m}^{3}$.

\section{IDEAL GAS MODEL}

In transient conditions, the energy balance equation for the ideal gas is:

$$
\begin{aligned}
& m\left[\frac{W^{2}}{2}+c_{v}\left(T-T_{R}\right)+R T\right]= \\
& =-\frac{\partial M}{\partial \tau} c_{v}\left(T-T_{R}\right)-M c_{v} \frac{\partial T}{\partial \tau}
\end{aligned}
$$

The mass balance equation reads as:

$$
M(\tau)=\rho(\tau) V \text { and }-\frac{\partial M}{\partial \tau}=m
$$

The mean velocity is linked to the mass flow rate:

$W=\frac{m}{\rho S}=-\frac{V}{S} \frac{1}{\rho} \frac{\partial \rho}{\partial \tau}$

As a consequence, the gas pressure is linked to the density, from Eq. (1), as follows:
$\frac{W^{2}}{2}=\frac{p-p_{o}}{\rho \beta}=\frac{V^{2}}{2 S^{2}} \frac{1}{\rho^{2}}\left(\frac{\partial \rho}{\partial \tau}\right)^{2}$

The pressure and its derivative are then:

$p=\frac{\beta V^{2}}{2 S^{2}} \frac{1}{\rho}\left(\frac{\partial \rho}{\partial \tau}\right)^{2}+p_{o}$
$\frac{\partial p}{\partial \tau}=\frac{\beta V^{2}}{2 \rho S^{2}} \frac{\partial \rho}{\partial \tau}\left[2 \frac{\partial^{2} \rho}{\partial \tau^{2}}-\frac{1}{\rho}\left(\frac{\partial \rho}{\partial \tau}\right)^{2}\right]$

The time derivative of temperature, for the ideal gas, is:

$\frac{\partial T}{\partial \tau}=\left(\frac{1}{\rho} \frac{\partial p}{\partial \tau}-\frac{p}{\rho^{2}} \frac{\partial \rho}{\partial \tau}\right) \frac{1}{R}$

Hence the Eq. (2) reads as:

$\frac{\partial \rho}{\partial \tau}\left[\frac{\partial^{2} \rho}{\partial \tau^{2}}-\frac{1}{2 \rho}\left(\frac{\partial \rho}{\partial \tau}\right)^{2} \frac{\gamma(1+\beta)+\beta-1}{\beta}-\frac{\gamma S^{2}}{\beta V^{2}} p_{0}\right]=0$

valid if $\rho \neq 0$. This is a second order differential equation, not linear and written in a not normal form (that means not singleness of the Cauchy's problem).

Nevertheless, the solution investigated is not easy to obtain.

The gas density decrease is expected at the initial moment, in which the tank is opened, hence $\partial \rho / \partial \tau \neq 0$.

By defining the new function:

$u(\rho)=\frac{\partial \rho}{\partial \tau}$

the Eq. (8) can be written as:

$u \frac{\partial u}{\partial \rho}-\frac{C_{1}}{2 \rho} u^{2}=C_{2}$ 
where the known constants $\mathrm{C}_{1}$ and $\mathrm{C}_{2}$ are:

$$
C_{1}=\gamma+1+\frac{\gamma-1}{\beta} \quad C_{2}=\frac{\gamma S^{2}}{\beta V^{2}} p_{o}
$$

The first order differential Eq. (10) requires, to be solved, a further definition:

$$
\mathrm{z}(\tilde{\mathrm{n}})=\mathrm{u}^{2}
$$

Hence the first order linear differential equation is obtained

$$
\frac{\partial z}{\partial \rho}-\frac{C_{1}}{\rho} z=2 C_{2}
$$

whose solution has the following form:

$$
z(\rho)=\rho^{C_{1}}\left(\frac{2 C_{2}}{1-C_{1}} \rho^{1-C_{1}}+K\right)
$$

with $\mathrm{K}$ constant of integration calculated by means of the initial condition.

Using the Eqs. (10) and (12), the solution (14) can be written as:

$\frac{\partial \rho}{\partial \tau}= \pm\left(\frac{2 C_{2}}{1-C_{1}} \rho+K \rho^{C_{1}}\right)^{\frac{1}{2}}$

The only solution with physical meaning is the negative one, because, when the tank is opened, the density of the gas is expected to drop.

The existence domain for the solution to the Eq. (15) is:

$\rho \geq\left(-\frac{2 C_{2}}{\left(1-C_{1}\right) K}\right)^{\frac{1}{C_{1}-1}}$

The steady state is represented by $\partial \rho / \partial \tau=0$, which implies:

$\rho *=\left(-\frac{2 C_{2}}{\left(1-C_{1}\right) K}\right)^{\frac{1}{C_{1}-1}}$

The density function $\rho$ is monotonically decreasing; it reaches its steady state at the time $\tau^{*}$, so that the solution to the problem is the solution to the Eq. (15) for $\tau \leq \tau^{*}$, the Eq. (17) for $\tau \geq \tau^{*}$.

Even any small oscillation of $\rho$, due to pressure waves spreading along the exhaust duct, can be ruled out by a qualitative analysis [5] of the differential equation. The phenomenon concerning the emptying of the tank ends after a $\tau^{*}$ time, just when the first derivative of $\rho$ is zero.

Coming back to the Eq. (15) and integrating it, starting from the initial state $\tau=0$, we get:

$\int_{0}^{\tau} d \tau^{\prime}=-\int_{\rho_{\text {in }}}^{\rho}\left(\frac{2 C_{2}}{1-C_{1}} \rho^{\prime}+K \rho^{\prime C_{1}}\right)^{-\frac{1}{2}} d \rho^{\prime}$

Unfortunately there is not an analytical solution to the Eq. (18). So, after having reduced the beginning linear differential equation in order to obtain a qualitative analysis of the solution, it is suitable resorting to a numerical analysis.

The solution to Eq. (8) has been numerically investigated using a dedicated software: Matlab. Matlab collects additional software modules, called "toolboxes", which perform specific tasks. Many of these toolboxes can be used to solve differential equations with constant coefficients. In particular, the Runge-Kutta method of second and third class [6], has been chosen to solve this model. The respective solver function of Matlab is "ode23"; it is a one step solver which solves initial value, moderately stiff problems.

\section{REAL GAS MODEL}

Looking at the intensive properties (pressure and temperature), for both initial state and critical point of air, the reduced coordinates have been computed and, resorting to the Nelson-Obert diagram [2], the compressibility factor has been calculated. It allows quantifying the real gas deviation from the ideal gas behaviour. Fearing the ideal gas hypothesis not reliable, a second model of calculation has been accomplished: the real gas model, according to Van der Waals equation:

$\left(p+\frac{a}{v^{2}}\right)(v-b)=R T$

Following the same procedure as for the ideal gas model, the energy balance equation reads as:

$$
\begin{aligned}
& \frac{\partial \rho}{\partial \tau}\left\{(1-b \rho) \frac{\partial^{2} \rho}{\partial \tau^{2}}-\frac{1}{2 \rho}\left(\frac{\partial \rho}{\partial \tau}\right)^{2}\left[\frac{R}{c_{v}} \frac{\beta+1}{\beta}+\right.\right. \\
& +2-b \rho]-\left(\frac{R}{c_{v}}+2 b \rho-1\right) \frac{a S^{2}}{\beta V^{2}} \rho^{2}+ \\
& \left.-\left(\frac{R}{c_{v}}+1\right) \frac{S^{2}}{\beta V^{2}} p_{o}\right\}=0
\end{aligned}
$$

valid if $\rho \neq 0$.

It can be observed that, if $a$ and $b$ were supposed negligible, the energy balance Eq. (20) would coincide with the differential Eq. (8) of the ideal gas model.

Solving this second order not linear differential equation, the behaviour the tank discharge can be described. Even in this case, the computation of the equation has been carried out numerically using Matlab, in particular the function solver "ode23".

Some more parameters of the air must be introduced, exactly: $\mathrm{a}=161.9\left(\mathrm{~m}^{3} / \mathrm{kg}\right)^{2} \mathrm{~Pa}, \mathrm{~b}=1.26 \times 10^{-3} \mathrm{~m}^{3} / \mathrm{kg}$ [2].

The density value at the initial state has been computed, being known pressure and temperature values, applying the Van der Waals equation. It is equal to $\rho_{\text {in }}=46.98 \mathrm{~kg} / \mathrm{m}^{3}$, slightly different from the value for the ideal gas model $\left(45.52 \mathrm{~kg} / \mathrm{m}^{3}\right)$.

\section{THE LOSS COEFFICIENT $\boldsymbol{\beta}$}

The coefficient $\beta$, defined by the Eq. (1), represents all the coefficients of mechanical losses (both concentrated and distributed) related to the flow in the control volume: 
$\beta=\sum_{1}^{n} \beta_{i}$

with $\beta_{\mathrm{i}}=\beta_{\mathrm{ci}}+\beta_{\mathrm{di}}$.

The computation of the coefficient $\beta$ has been carried out by means of a dedicated literature [7], presenting a huge collection of tables and charts for every kind of pressure loss encountered by a fluid stream.

By the results obtained [7], it comes up that the distributed losses just represent $5 \%$ of the total losses. This gives reason to the initial hypothesis: the coefficient of mechanical losses $\beta$ is particularly affected by the concentrated mechanical losses, i.e. by the duct geometry. For the particular geometry here considered, the loss coefficient is $\beta=39.93$ [7].

\section{RESULTS}

This section shows the perfect gas model results. These results have been obtained introducing into the model, not only the known parameters related to gas properties, system

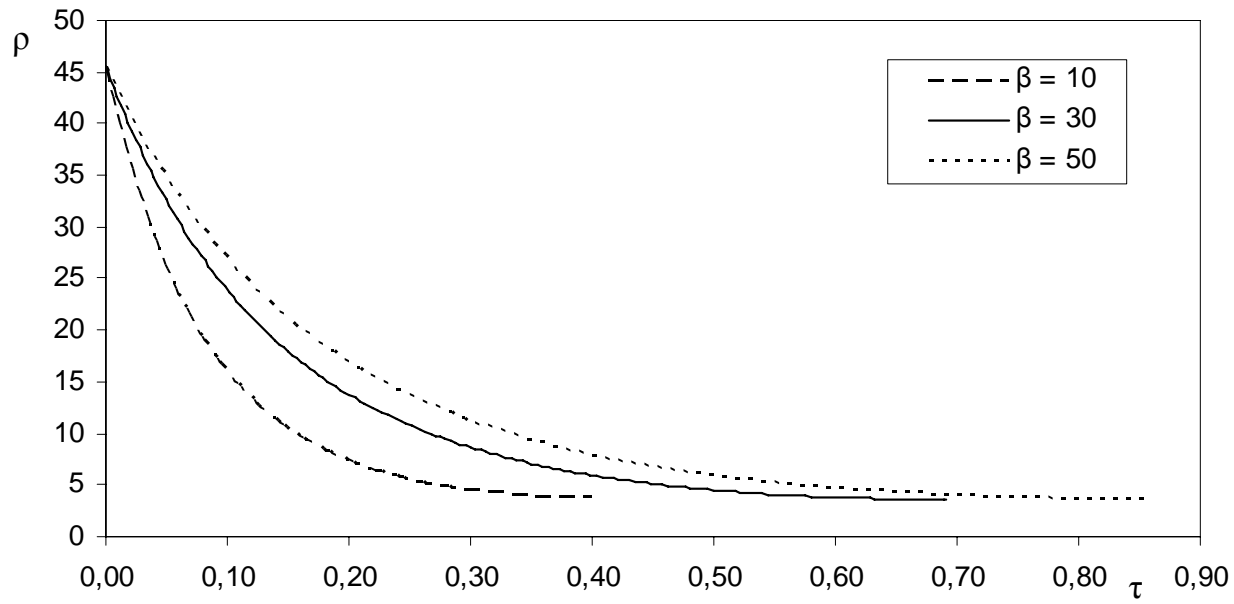

Fig. (2). Transient air density within the open thermodynamic system.

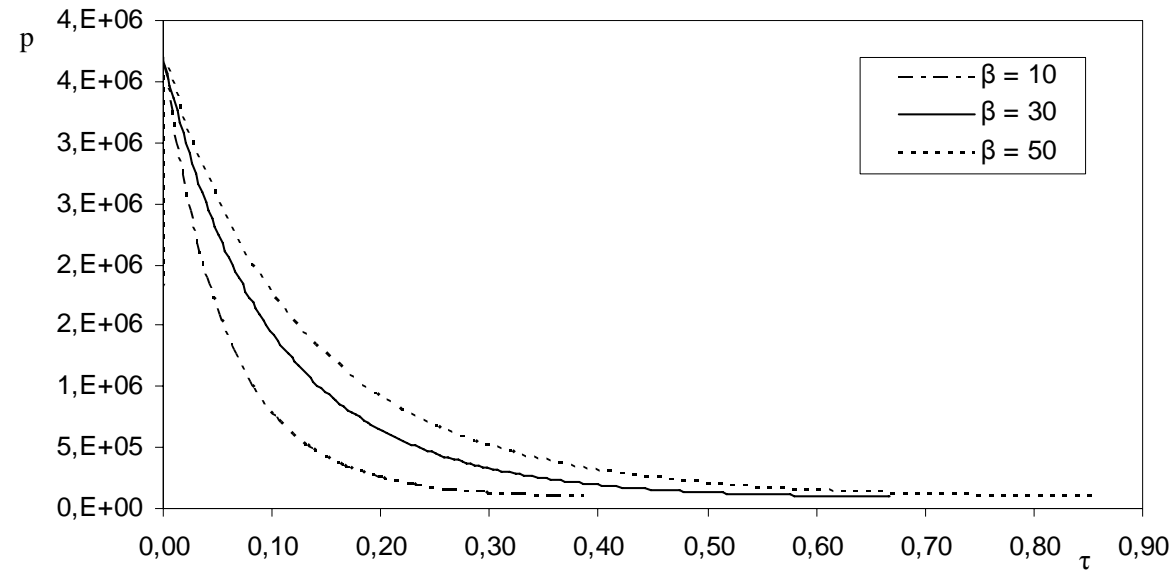

Fig. (3). Absolute air pressure within the open thermodynamic system.

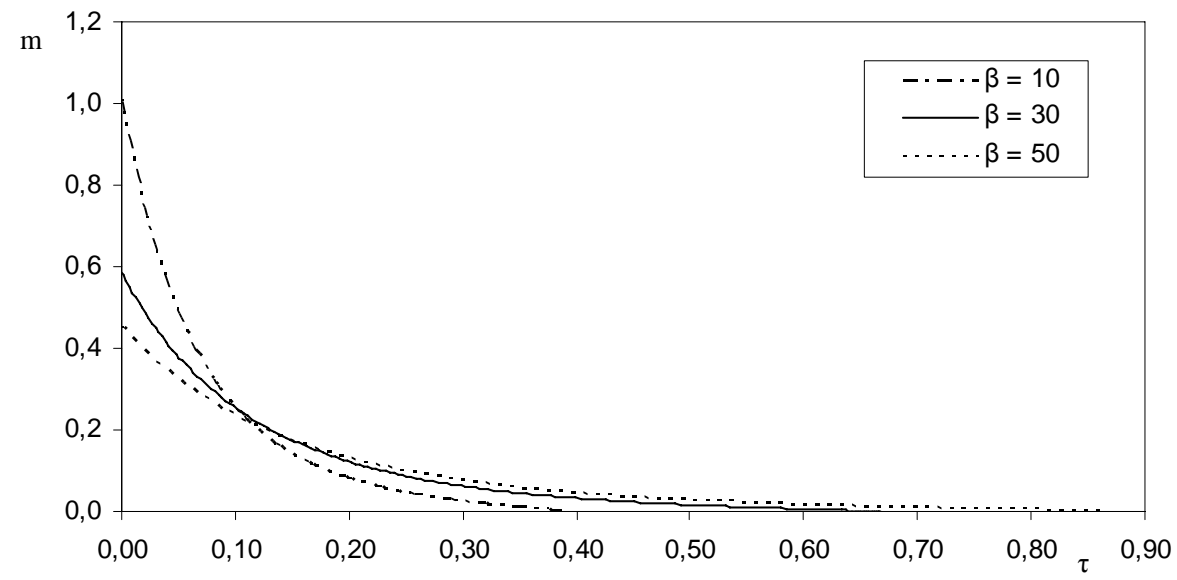

Fig. (4). Airflow rate from the open thermodynamic system. 


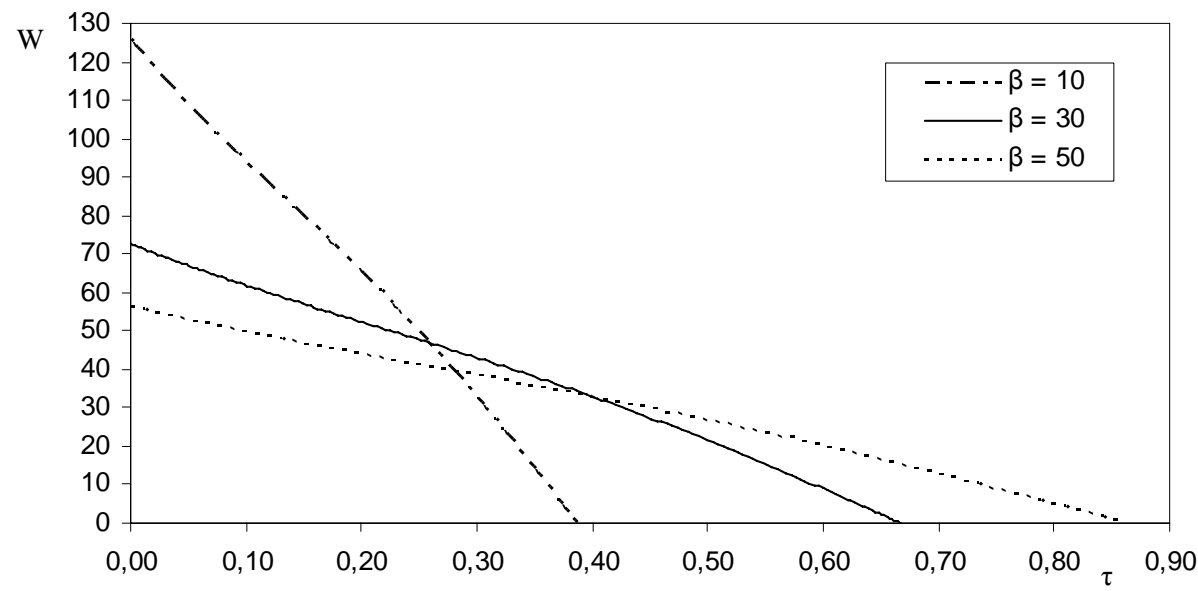

Fig. (5). Air velocity in the outflow section during the transient.

geometry, and boundary and initial thermodynamic conditions, but also the coefficient of mechanical losses $\beta$.

Figs. (2-5) represent a comparison between the time evolution of density, pressure, flow rate and gas velocity according to ideal gas model for three different values of the coefficient $\beta$.

Introducing into the ideal and real gas models, the value of $\beta$ computed for the blowing machine, and looking at the moment in which the gas density derivative becomes zero, that is the same in which the air pressure reaches the atmospheric value, we are able to know the time needed to complete the exhaust phase:

$$
\left\{\begin{array}{l}
\tau=0.7695 \mathrm{~s} \text { Perfect gas model } \\
\tau=0.7705 \mathrm{~s} \text { Real gas model }
\end{array}\right.
$$

As the mechanical losses appeared to be mostly concentrated into the double effect cylinder, a test was carried out on the cylinder, using two digital manometers (to measure pressure upstream and downstream), a Pitot tube (to measure average velocity) and a thermocouple. Following

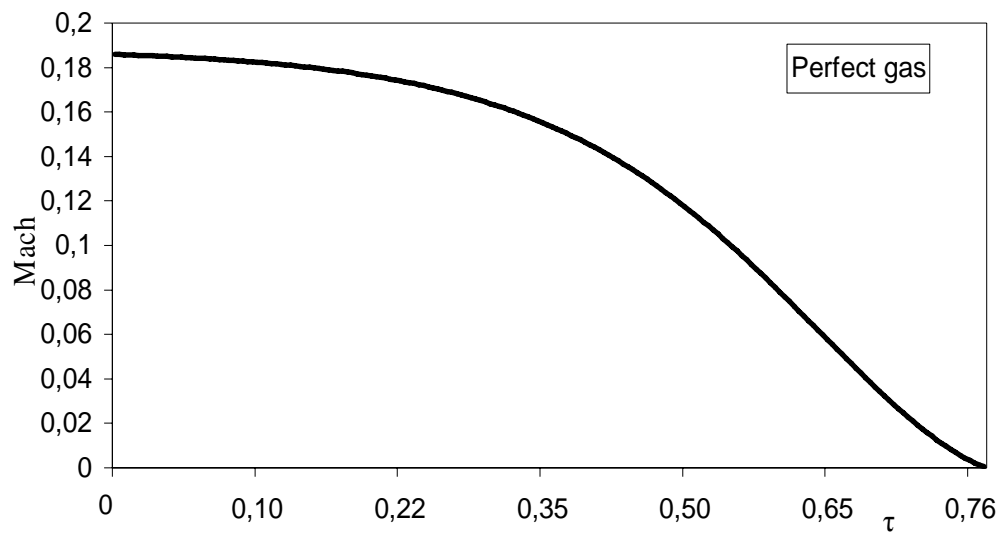

Fig. (6). Mach number during the discharge transient.

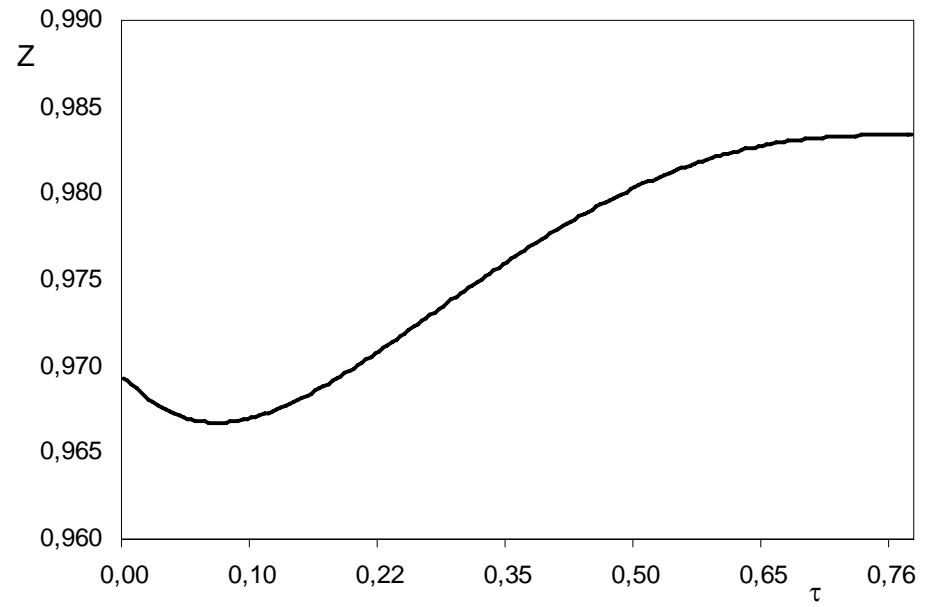

Fig. (7). Compressibility factor evolution during the discharge transient. 
the results of the experimental tests [1], the time required by the blowing machine, to discharge the quantity of air needed to shape a plastic bottle $\left(1.5 \mathrm{dm}^{3}\right)$ is about $0.7 \div 0.8 \mathrm{~s}$.

In Fig. (6) the Mach number is reported in the exit section, during the discharge transient. It is always less than unit. This result let us say the air discharge from a blowing station happens with a subsonic motion.

The comparisons concerning results obtained with ideal gas and real gas models, show a considerable similarity. This consideration is analytically proven; in fact Fig. (7) shows that the compressibility factor, calculated with the equation:

$$
Z=\frac{p}{R \rho T}
$$

is about a unitary value during the entire transient.
With the purpose of reducing the time required to carry out the complete outflow of the gas (that means to increase the machine performance) the possibility to decrease the coefficient of mechanical losses $\beta$ has been investigated. Paying attention to the geometric components, in particular the two bushings of the stem set into the double effect cylinder, which appeared to be the major obstacles to the air flow, and modifying properly their geometry, the coefficient $\beta$ has been reduced from 39.93 to 25.95 .

Introducing the new value of $\beta$ into the ideal and real gas models, it has been found a reduced time for the discharging phase:

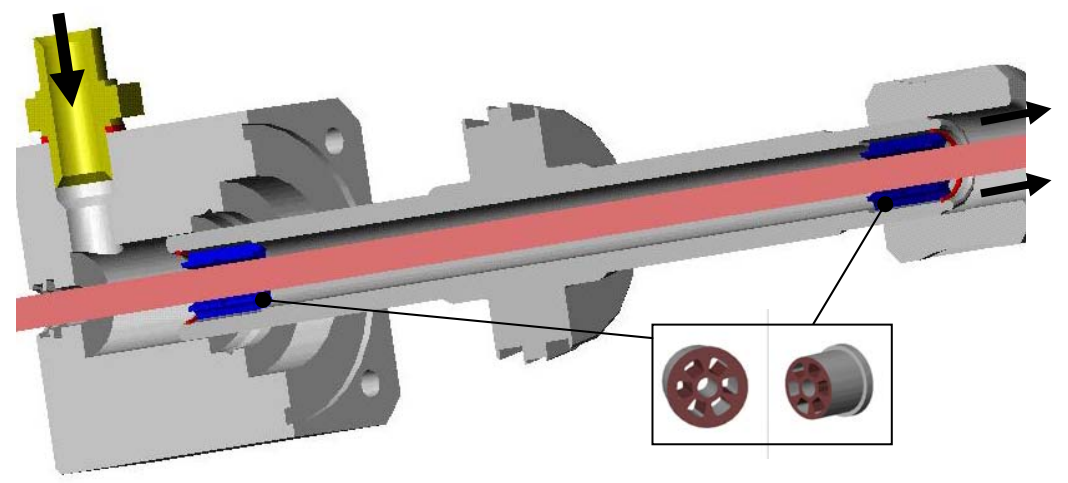

Fig. (8). Section view of the air discharging flow into the stretch-blowing unit, with a zoom view of the stem bushings.

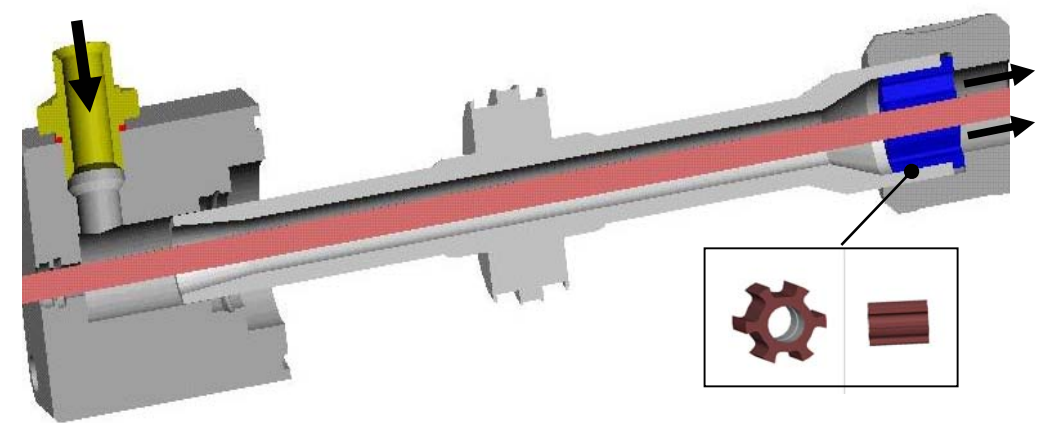

Fig. (9). Section view of the air discharging flow into the stretch-blowing unit, with a zoom view of the stem bushings, after the optimisation

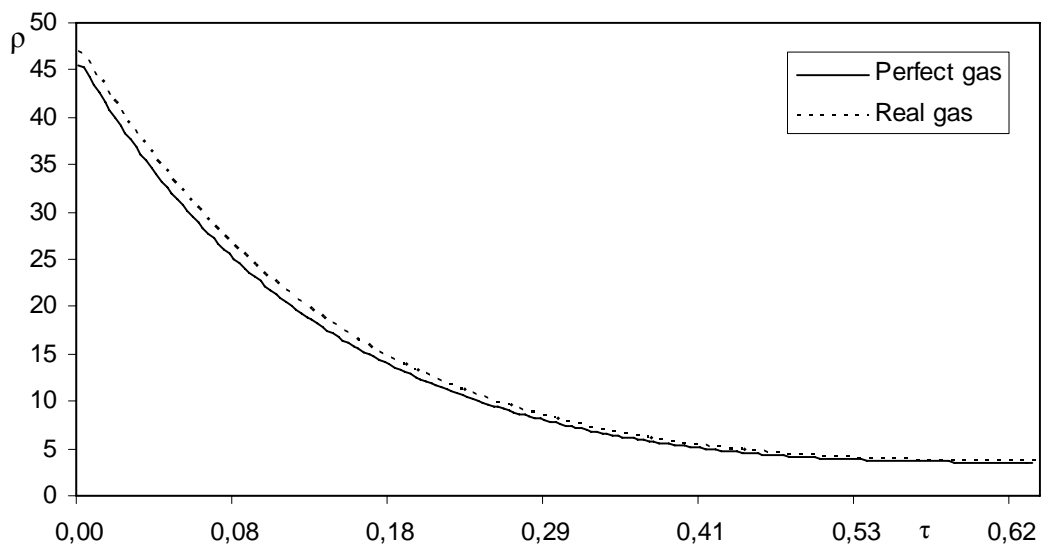

Fig. (10). Air density evolution during discharging phase, after the optimisation of the duct geometry. 


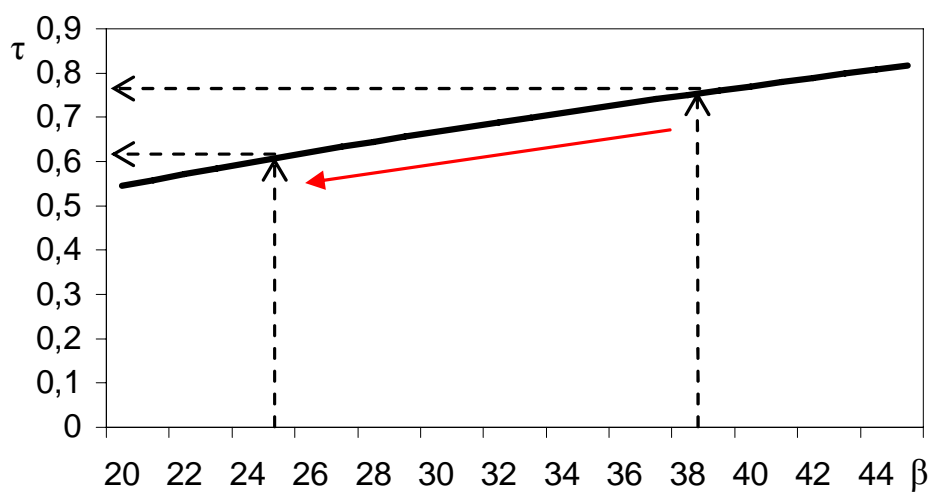

Fig. (11). Time of the discharging phase as a function of the coefficient of mechanical losses.

The stretch-blowing unit is shown in Figs. (8-9), focusing the stem bushings before and after the optimization, respectively.

Fig. (10) shows the air density evolution during the transient.

Fig. (11) shows the required time for the discharging phase, as a function of the coefficient of mechanical losses.

\section{CONCLUSIONS}

In this study, a numerical model has been carried out in order to analyze the discharging phase of air from a blowing machine. The model of simulation is based on the laws of thermodynamic governing the outflow of a compressible gas from an open system.

The mechanical losses, due to each geometrical singularity of the ducts crossed by the air, have been estimated. The discharging path has been modified in order to reduce their relevance. An investigation how the exhaust phase length is affected by the total coefficient of mechanical losses was carried out.

The geometry optimisation of the discharging path showed a reduction of the coefficient $\beta$ of $35 \%$ and a discharging time reduction of $20 \%$ that means to increase the blowing machine efficiency.

Another parameter affecting the time reduction is the air temperature at the beginning of the discharging phase into the blowing unit.

The real gas model and the ideal gas model give very similar results, being the compressibility factor $\mathrm{Z}$ very close to unity. Future work will be focussed on the 3-D gas velocity and temperature, obtained through numerical analysis, slightly simplified by the ideal gas model.

\section{GLOSSARY}

$\mathrm{a} \quad=$ Van der Waals coefficient in Eq. (19); $\left(\mathrm{m}^{3} / \mathrm{kg}\right)^{2} \mathrm{~Pa}$

$\mathrm{b}=$ real gas covolume; $\mathrm{m}^{3} / \mathrm{kg}$

$\mathrm{C}_{1}=$ dimensionless coefficient

$\mathrm{C}_{2}=$ constant $; \mathrm{kg} / \mathrm{m}^{3} \mathrm{~s}^{2}$

$c_{\mathrm{p}}=$ specific heat at constant pressure; $\mathrm{J} / \mathrm{kg} \mathrm{K}$

$\mathrm{c}_{\mathrm{v}}=$ specific heat at constant volume; $\mathrm{J} / \mathrm{kg} \mathrm{K}$

$\mathrm{K}=$ constant of integration for the Eq. (14) $\mathrm{m} \quad=$ gas mass flow rate; $\mathrm{kg} / \mathrm{s}$

$\mathrm{M} \quad=$ air mass into the tank; $\mathrm{kg}$

$\mathrm{Ma}=$ Mach number $\mathrm{W} / \mathrm{W}_{\mathrm{s}}$

$\mathrm{n}=$ number of singularities along the discharging path

$\mathrm{p} \quad=$ pressure $\mathrm{Pa}$

$\mathrm{p}_{0} \quad=$ atmospheric gas pressure; $\mathrm{Pa}$

$\mathrm{R}=$ ideal gas specific constant; $\mathrm{J} / \mathrm{kg} \mathrm{K}$

$\mathrm{S} \quad=$ gas outlet section surface; $\mathrm{m}^{2}$

$\mathrm{T} \quad=$ gas temperature; $\mathrm{K}$

$\mathrm{T}_{\mathrm{R}}=$ conventional temperature corresponding to zero value of the gas internal energy; $\mathrm{K}$

$\mathrm{v}=$ specific gas volume; $\mathrm{m}^{3} / \mathrm{kg}$

$\mathrm{V}=$ tank volume; $\mathrm{m}^{3}$

$\mathrm{W}=$ average gas velocity; $\mathrm{m} / \mathrm{s}$

$\mathrm{W}_{\mathrm{s}}=$ sound velocity in the gas; $\mathrm{m} / \mathrm{s}$

$\mathrm{Z}=$ compressibility factor

\section{GREEK SYMBOLS}

$\beta=$ mechanical loss coefficient

$\gamma=c_{\mathrm{p}} / \mathrm{c}_{\mathrm{v}}$ ratio

$\rho \quad=$ gas density $; \mathrm{kg} / \mathrm{m}^{3}$

$\rho^{*} \quad=$ steady state density defined in Eq. (17); $\mathrm{kg} / \mathrm{m}^{3}$

$\tau=$ time; $\mathrm{s}$

$\tau^{*} \quad=$ instant time corresponding to $\rho(\tau)=\rho^{*}$

\section{SUBSCRIPTS}

c $=$ concentrated mechanical losses

$\mathrm{d}=$ distributed mechanical losses

$\mathrm{i}=$ singularity along discharging path

in $\quad=$ initial time, $\tau=0$

\section{ACKNOWLEDGEMENTS}

The contribution of SIG Simonazzi SpA Noceto (Parma, Italy) is gratefully acknowledged. 


\section{REFERENCES}

[1] SIG Simonazzi, Noceto, Parma, Italy, personal communication. 2004.

[2] K. K. Jr Wark, Thermodynamics. McGraw-Hill, $5^{\text {th }}$ ed., New York, 1988.

[3] E. M. Greitzer, C. S. Tan and M. B. Graf, Internal Flow, Cambridge University Press, 2004.

[4] K. Raznjevic, Handbook of Thermodynamic Tables, Begell House Inc., New York, 1995.
[5] M. Abramowitz and I. A. Stegun, Handbook of Mathematical Functions, Dover Publications Inc., New York, 1972.

[6] T. L. Barman, J. Dabney and N. Richert, Advanced Engineering Mathematics with Matlab, Brooks/Cole, Pacific Grove, 2000.

[7] I. E. Idel'cik, Mémento des pertes de charge, Editions Eyrolles, Paris, 1986.

Received: March 30, 2008

Revised: May 07, 2008

Accepted: November 14, 2008

(C) Antinori and Spiga; Licensee Bentham Open.

This is an open access article licensed under the terms of the Creative Commons Attribution Non-Commercial License (http://creativecommons.org/licenses/bync/3.0/), which permits unrestricted, non-commercial use, distribution and reproduction in any medium, provided the work is properly cited. 